\title{
INFLUENCE OF HYDROGEOLOGICAL AND GEOTECHNICAL PARAMETERS ON THE SEISMIC BEHAVIOR OF POTABLE WATER INFRASTRUCTURES
}

\author{
RAMÓN EGEA PÉREZ ${ }^{1}$, JESÚS P. CHAZARRA ZAPATA² \& FRANCISCO J. LÓPEZ PEÑALVER ${ }^{3}$ \\ ${ }^{1}$ EMUASA, Municipal Water and Sanitation Company, Murcia, Spain. \\ ${ }^{2}$ Engineering Department, University Miguel Hernandez, Orihuela (Alicante), Spain. \\ ${ }^{3}$ Superior Polytechnic School, Alicante University, Spain.
}

\begin{abstract}
This study analyzes the influence of the urban hydraulic infrastructure behavior, the soil typology and the characterization of the hydrogeological zonal risks, proposing constructive dispositions and procedures, which will increase the reliability of the pipes consisting of a fragile nature, guaranteeing the service continuity even during seismic events with intensity higher than VII (IMM). That would greatly reduce the degree of vulnerability of the urban hydraulic infrastructure, especially in the case of Southeast Spain, which presents a high risk of seismic intensity. Although the effects on the vulnerability of pipelines, of the displacement of the ground, such as fault movements, settlements and lateral expansions, have been widely studied and analyzed, there is no comprehensive methodology, incorporating other factors related to the Management of the infrastructure, and therefore a general application method is proposed that will evaluate in addition to the effects according to the soil typology and the hydrogeological characteristics zonal (hydrological hazard, seismic hazard, and specific hydrogeological factors), the typology of the infrastructure linear hydraulic, based on operational analysis, that allows to correlate the behavior of the soils and the possible affectation in the potable water pipes, thus serving as planning element and preventive tool for the mitigation of damages.
\end{abstract}

Keywords: ground motion, hazard, hydrological, liquefaction, management, risk, seismic, vulnerability

\section{INTRODUCTION}

As it has been observed in different earthquakes, saturated, weakly cohesive granular soils are more susceptible to an increase in the interstitial pressure of the water, causing very loose sands and loss of initial resistance to cutting. The increase in interstitial pressure in the pores generates the amplitude of the oscillatory filtration, according to the size, shape and gradation of the particles, the confinement pressure acting on the soil, the texture of the soil and the rate of over-consolidation of this.

According to Japanese experiences, the damage in linear underground hydraulic infrastructures is much greater in the earthquakes associated with the liquefaction of the soil than in those that are not associated with that effect, the soils being more susceptible, those of flat topography. Therefore, large deformations in the ground are not easily perceived, which makes it difficult to determine the type of soil deformation, which has caused damage in a pipe following a seismic movement.

In general, there are two forms of seismic deformation in the soil, linked to the liquefaction and that could cause damage to buried pipes:

- The dynamic deformation or alternating tension and compression.

- Static strain or tension in one direction.

In addition, in buried pipes, ascending hydrostatic pressures (saturated soils whose behavior can be assimilated to a static fluid) can be produced by the favor buoyancy of the same, 
causing ruptures or superficiality of these, as well as an increase of the pressure of water contained in the pores of the soil that favors behavior [1].

Impacts on pipeline vulnerability, land displacement, such as fault movements and lateral expansions, although widely studied, have not yet been proposed for a general application method that assesses the effects of soil-based conditions in a statistical analysis, which allows to correlate the characteristics of behavior of the soils and the susceptibility to the damages of the pipes according to their nature, and constructive disposition.

According to the existing statistics based on different earthquakes occurring in Japan, New Zealand, Mexico, Chile, Italy and other countries with significant seismic activity, and as indicated, it has been verified by the following:

- Damage is concentrated in areas where irregular terrain conditions occur; being the nonuniformity of the displacement generated as a product, in turn, of the variability in the nature of the terrain, the cause of the greater deformations of the soil.

- The degree of vulnerability depends to a large extent on the type of piping system and its material nature. Depending on the material used, less flexibility of the pipe or its joints, greater effect on the vulnerability of linear infrastructure is generated.

- The vulnerability also depends on the intensity of the seismic movement, which is represented by the maximum acceleration [2].

It is for this reason that liquefaction - enhanced by the characteristics of the original subsurface - is considered the main cause of damage in the piping system during a seismic movement. As one of the specific damages, the lifting and/or displacement of the pipes, is due to the following occurrences or factors:

- The existence of a liquefied layer of land exerting a pressure or push on the top layer of soil.

- The location of an impermeable layer, which precludes or limits the dissipation of the water high pressure in the pores of the land.

- The generation of an amplification of the seismic movement, increasing the degree of liquefaction of the land located on the lower layer of the subsoil.

The impacts of seismic movement on hydraulic infrastructures, and more specifically on pipes and fittings, may vary to a greater or lesser degree, depending on the following factors:

Geology, geotechnics and characterization of local underground hydrology:

- Nature and characteristics of the land.

- Variability and power of strata constituting of the land.

- Existence of groundwater levels and their seasonal variability.

- Geology and geotechnics of the area.

- Contamination of sources and areas of surface runoff.

Typology and characteristics of linear hydraulic infrastructure:

- Type of pipe.

- Nature of the pipe material.

- Type of installation.

- Buried or surface pipeline.

- Possible interaction with other linear infrastructures (roads, railways, oil pipelines, power lines and telecommunications). 
Next, in the organizational chart of Fig. 1, the process of the seismic action on the infrastructure, related to the zonal geology is described.

In the case of Southeastern Spain, and especially the City of Murcia, whose seismic hazard is moderate, presents a characterization of soils, Fig. 2, especially susceptible to liquefaction and subsidence phenomena, increased by other adverse climatological factors, such as the aridity of the territory and periodic droughts, heavy rains [3].

\section{SEISMIC CHARACTERIZATION}

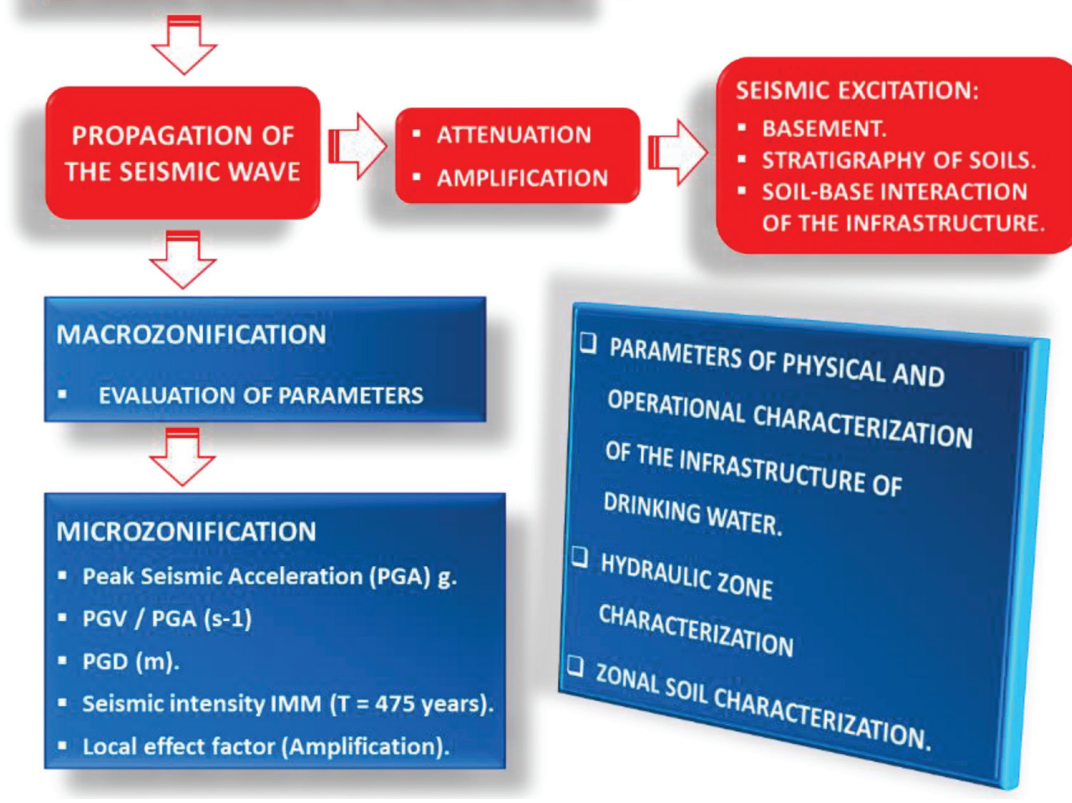

Figure 1: Organization chart of the characterization of the seismic risk and its geological component in relation to the Infrastructure of the drinking water network.

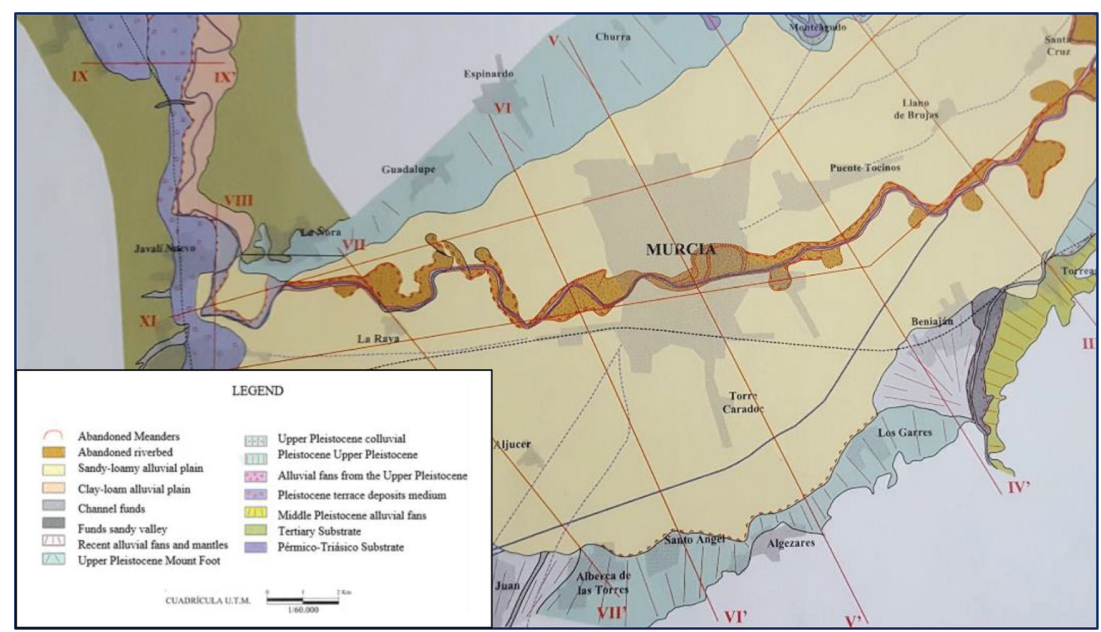

Figure 2: Geological map of quaternary surface formations metropolitan area of the city of Murcia. (Source: IGN). 


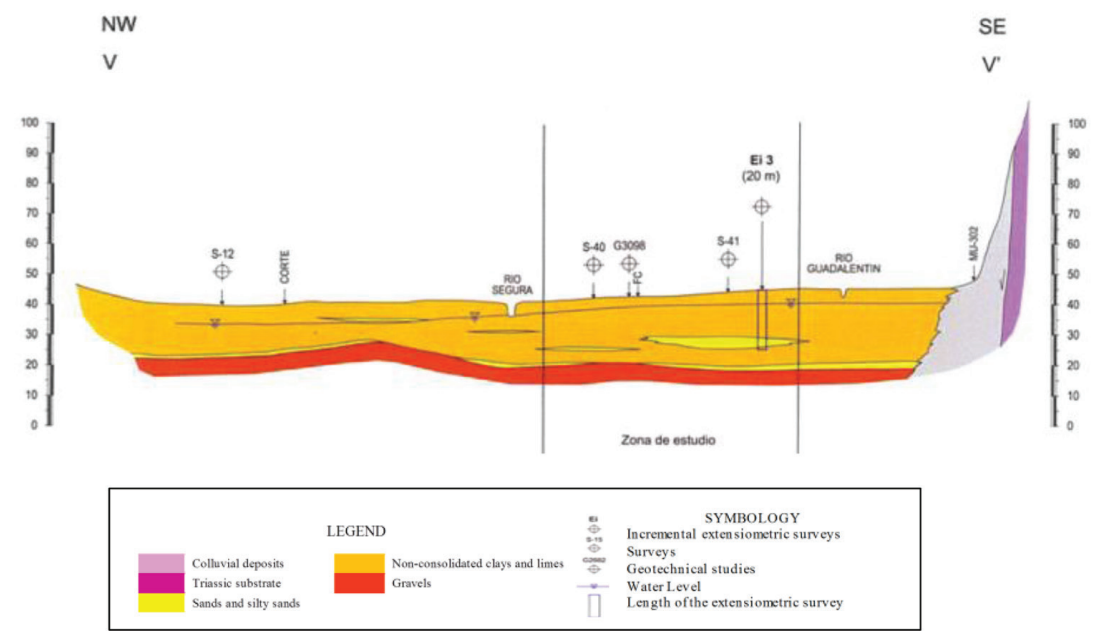

Figure 3: Geological profile representative of the urban nucleus of the city of Murcia (VV '). Scale 1:1250. (Source: IGN)

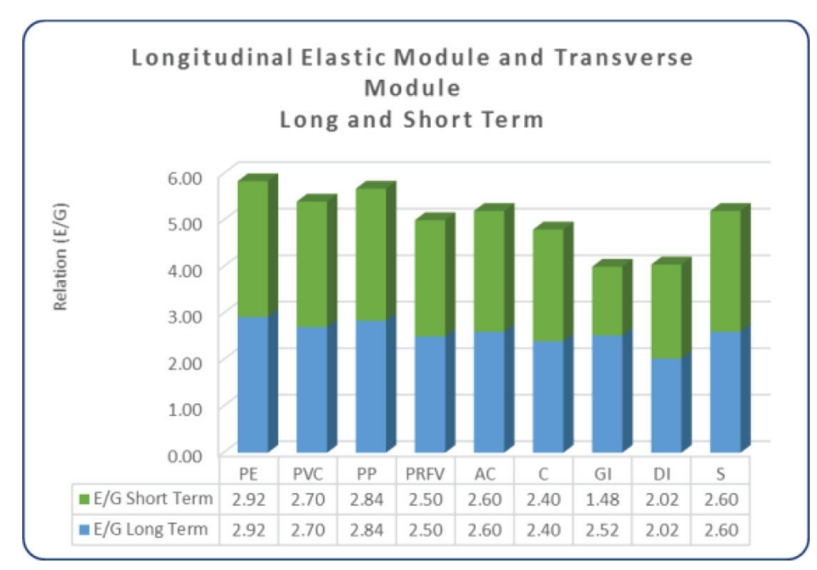

Figure 4: Relationship between longitudinal and transverse elastic modules, and drinking water piping materials. (EMUASA).

The metropolitan area of Murcia City is also located in an alluvial plain characterized by fillers and anthropic material in the superficial strata, cemented on colluvial lands and surface aquifers, Fig. 3.

The following are the areas of the city of Murcia that are more vulnerable to hydrogeological risks, especially flood and seismicity. It is remarkable, the areas near the river Segura, where the old abandoned meanders appear, and where the most superficial layers of land, settle on alluvial floodplains. In these circled areas, the characterization of the type $\mathrm{V}$ and type VI soil makes them especially susceptible to the liquefaction phenomenon in case of seismic movement, and this contributes to the fact that the expected maximum seismic acceleration (PGA), Fig. 4 and Table 1, in these zones can reach values of $0.24 \mathrm{~g}$ for an estimated seismic intensity of grade VII (IMM). In this, case, the effects of that intensity are enhanced by the 'site effect' by a factor, $\mathrm{Fa}=2.5$ (Borcherdt, 1994a, 1994b), [4]. 
Table 1: Amplification factors for different soil types and base acceleration values, PGA. (Source: RISMUR-Update 2015), [2].

\begin{tabular}{|c|c|c|c|c|c|c|c|}
\hline \multirow[b]{2}{*}{ PGA } & \multirow{2}{*}{$\begin{array}{l}\text { Site class } \\
\text { FEMA } \\
\text { (NEHRP- } \\
2009 \text { ) }\end{array}$} & \multicolumn{5}{|c|}{$\begin{array}{l}\text { Mapped MCE geometric mean peak ground acceleration, } \\
\text { PGA }(\mathrm{g})\end{array}$} & \multirow{2}{*}{$\begin{array}{l}\text { Site class } \\
\text {-RISMUR } \\
2015\end{array}$} \\
\hline & & $\mathrm{PGA} \leq 0.1$ & $\mathrm{PGA} \leq 0.2$ & $\mathrm{PGA} \leq 0.3$ & $\mathrm{PGA} \leq 0.4$ & $\mathrm{PGA} \leq 0.5$ & \\
\hline 0 & A & 0.80 & 0.80 & 0.80 & 0.80 & 0.80 & $\begin{array}{l}\text { I } \\
\text { Null }\end{array}$ \\
\hline 0.1 & B & 1.00 & 1.00 & 1.00 & 1.00 & 1.00 & $\begin{array}{l}\text { IIa } \\
\text { Very low }\end{array}$ \\
\hline 0.2 & $\mathrm{C}$ & 1.20 & 1.20 & 1.10 & 1.00 & 1.00 & $\begin{array}{l}\text { IIb } \\
\text { Low }\end{array}$ \\
\hline 0.3 & $\mathrm{C}$ & 1.20 & 1.20 & 1.10 & 1.00 & 1.00 & $\begin{array}{l}\text { IIIa } \\
\text { Half }\end{array}$ \\
\hline 0.4 & $\mathrm{D}$ & 1.60 & 1.40 & 1.20 & 1.10 & 1.00 & $\begin{array}{l}\text { IIIb } \\
\text { Half }\end{array}$ \\
\hline 0.5 & $\begin{array}{l}\mathrm{D} \\
\mathrm{E}\end{array}$ & $\begin{array}{l}1.60 \\
2.50\end{array}$ & $\begin{array}{l}1.40 \\
1.70\end{array}$ & $\begin{array}{l}1.20 \\
1.20\end{array}$ & $\begin{array}{l}1.10 \\
0.90\end{array}$ & $\begin{array}{l}1.00 \\
0.90\end{array}$ & $\begin{array}{l}\text { IV High } \\
\text { V High }\end{array}$ \\
\hline & $\mathrm{F}$ & Zonal speci & ific study & & & & VI Very High \\
\hline
\end{tabular}

The marked areas correspond to locations that are particularly vulnerable to hydrogeological phenomena, with a potential risk of liquefaction and differential settlements, Figs 5 and 6, so that existing drinking water supply networks must be subject to strict controls, the incorporation of resilient elements and the planning of actions that guarantee the continuity of operation, according to the elastic modulus of the pipe material, Fig. 7.

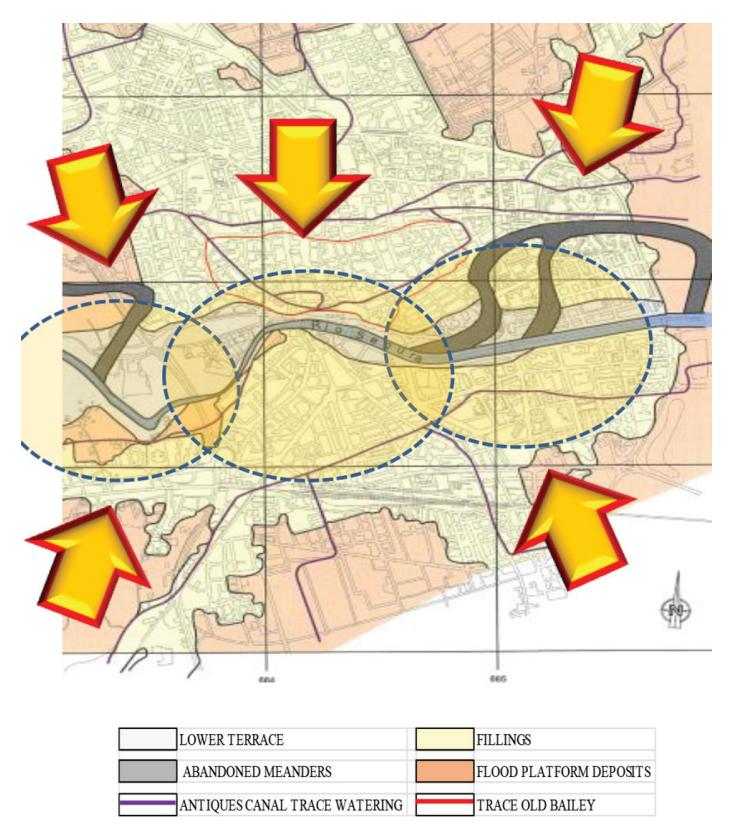

Figure 5: Geological Map of the City of Murcia at scale 1/12,500 (Source: IGN) 


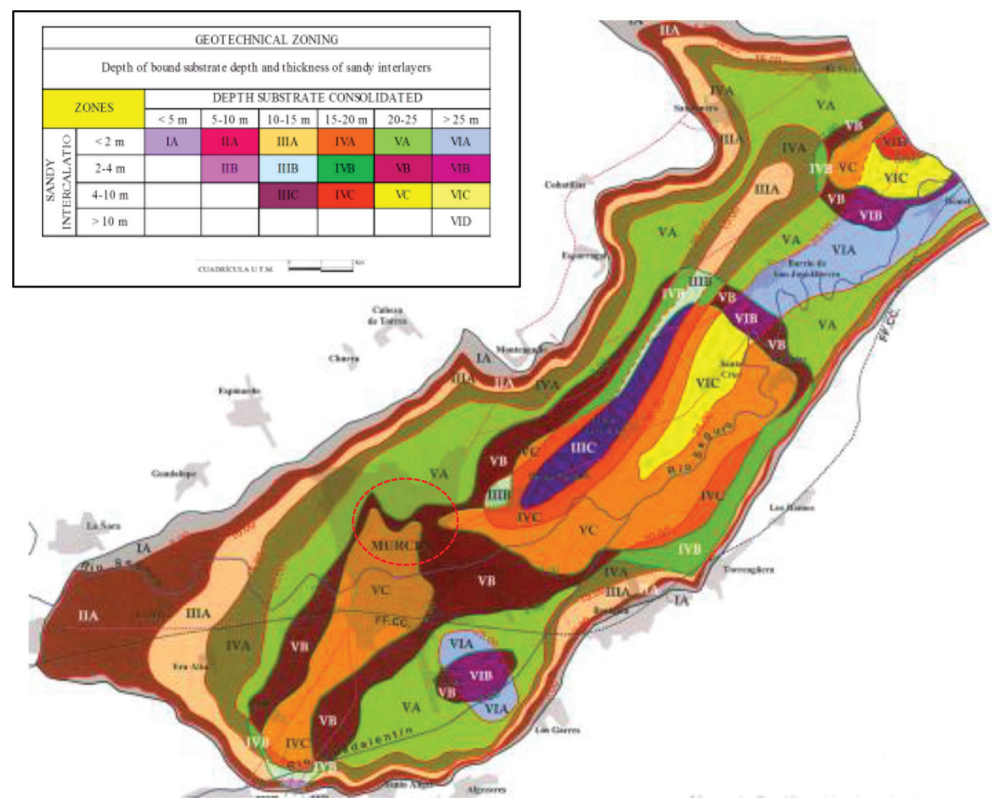

Figure 6: Map of geotechnical zoning of the middle Vega of the Segura River. (Source: IGN)

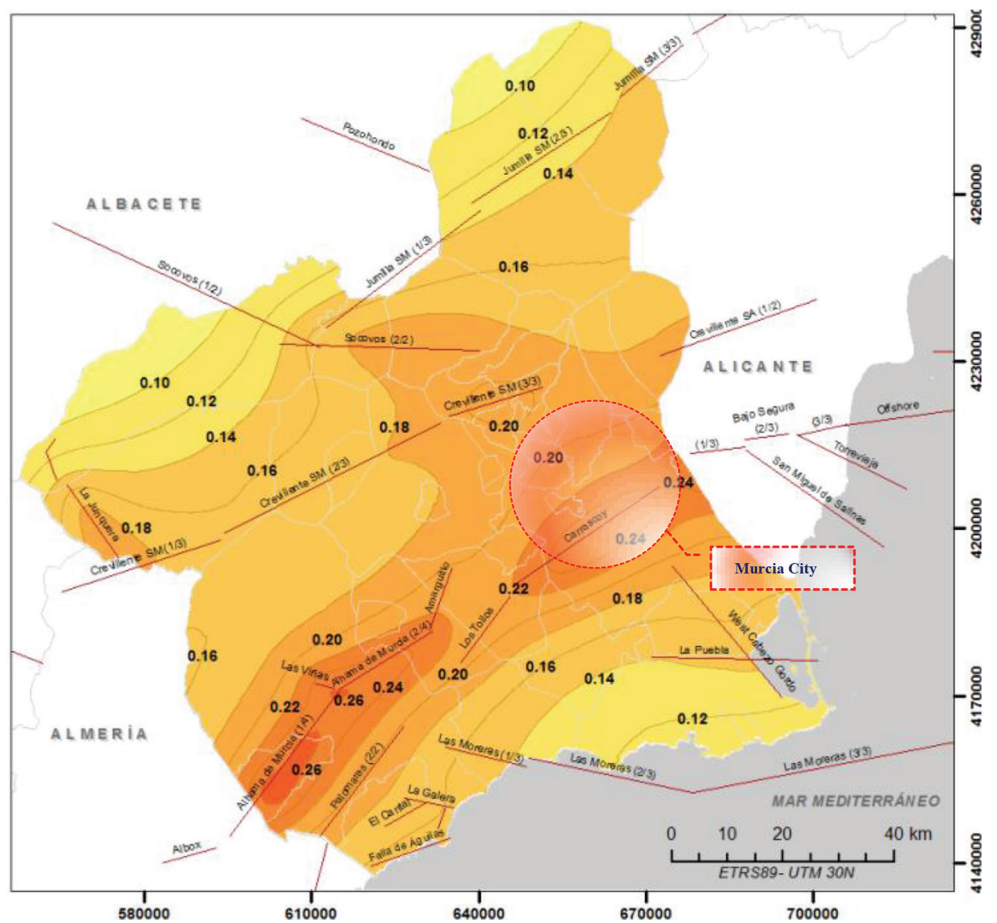

Figure 7: Map of seismic hazard in rock of the region of Murcia for periods of return of 475 years. Average maximum accelerations of the horizontal components of the PGA movement $(\mathrm{g}),[11]$. 


\section{METHODOLOGY}

The analysis of the geotechnical parameter and the selection of the most representative ones in their interaction with the effects generated by seismic and hydrological events, is essential to provide the linear hydraulic infrastructure (supply and sanitation networks) with a response capacity or of sufficient resilience to guarantee the operation of the System and to counteract the intensity of the natural event that occurred [5-9].

The parameters to be considered in the risk assessment of the linear hydraulic infrastructure are:

- Tectonic movement:

- Characterization of the active fault.

- Seismic return period.

- Directionality of the fault.

- Soil movement: PGV, PGA

- Liquefaction: the susceptibility of the ground to the displacement can be up to 10 times greater than in normal conditions. If the terrain topography is flat, there is no lateral displacement.

- Side propagation (PGD).

- Landslide.

- Differential settling.

- Shaking.

To estimate the damage to the components of the linear infrastructure, it must be characterized based on:

- Material of the pipe.

- Type of retention joint or joint.

- Length of the pipe.

- Medium conditions and definition of the elements of protection against corrosion.

As a measure of damage mitigation, it is necessary to characterize the soils, and the seismic or hydrological potential of the area, if applicable. For this, the degree of affectation of the linear hydraulic infrastructure and the evolution of the soil-infrastructure interaction are evaluated and defined, due to the occurrence of effects generated by an earthquake.

The basic parameters, which define the linear water infrastructure, as well as other local geological and geotechnical parameters that must be characterized, are summarized in the following tables (Table 2).

Different phases of proposed geological a geotechnical parameter influence value methodology is described below in schematic form. Some of those were analyzed and defined earlier (Fig. 8).

\section{RESULTS AND DISCUSSION}

The analysis of the proposed characterization model leads to the establishment of preventive measures and planning of actions to be carried out, as well as to provide operational management of the potable water distribution system with fundamental information to limit the impact of a seismic event, and increase the reliability of the Hydraulic Infrastructure, Fig. 9. 
Table 2: The parameters that define the linear infrastructure of drinking water, in relation to the geological and local geotechnical characterization.

\section{Physical characterization Hydraulic sector or sub-sector}

Hydraulic sector designation:

Location (UTM):

Designation pressure zone:

Nature (material) and length networks $(\mathrm{km})$ :

Ductile cast iron-DF $(\mathrm{km})$ :

Polyethylene-PEHD $(\mathrm{km})$ :

Steel-S (km):

Gray-GF casting $(\mathrm{km})$ :

Asbestos cement-AC $(\mathrm{km})$ :

$\mathrm{Sr}$ (relative rigidity) Tons $/ \mathrm{m}^{2}$ :

Average age of the network by type of material (years):

Number of sectorization valves (units)

Max. Pipe (mm):

No counters zone (uds):

\section{Operational characterization of the Hydraulic sector or subsector}

Average supply pressure (m.c.a.):

Number of breaks/km net (hydraulic basin or sub-basin):

Degree of criticality (I-IV) from lowest to highest:

Strategic supply (Yes/No)

Network class:

Tertiary network (Yes/No)

Secondary network (Yes/No)

Primary Network (Yes/No)

Transport network (Yes/No)

Existence of alternative supply (Yes/No):

Supply flow $\left(\mathrm{m}^{3} / \mathrm{h}\right)$ :

Q average ( $1 / \mathrm{s})$

Qmax. (L/s)

Water quality:

Dosage chlorination ( $\mathrm{NaClO}$ ) mgr/1-ppm:

Turbidity index (NTU)

Type of maintenance:

I - VI (lowest to highest grade)

Seismic zone definition:

Peak seismic acceleration (PGA) g:

PGV/PGA (s-1):

PGD (m):

Seismic intensity IMM $(\mathrm{T}=475$ years $)$ :

Local effect factor (amplification): 
Table 2: (Continued)

\section{Hydrological definition}

Flood zone (Yes/No):

No. of flood episodes/year:

Average height of water $(\mathrm{m})$

Maximum terrain slope (\%):

Coef. Runoff $(\mathrm{C})$ :

\section{Geological and geotechnical characterization}

Soil typology (RISMUR-2015 classification) (I-VI)

Permissible voltage or load bearing capacity $\left(\mathrm{N} / \mathrm{mm}^{2}\right)$ :

N30 (SPT):

Phreatic level depth (m):

\section{Complementary characterization}

Artistic heritage area (Yes/No)

Number of inhabitants (Inhab.)

Location of strategic centers (YES/No):

Existence health centers (Yes /No):

Existence of other critical infrastructures (Yes/No):

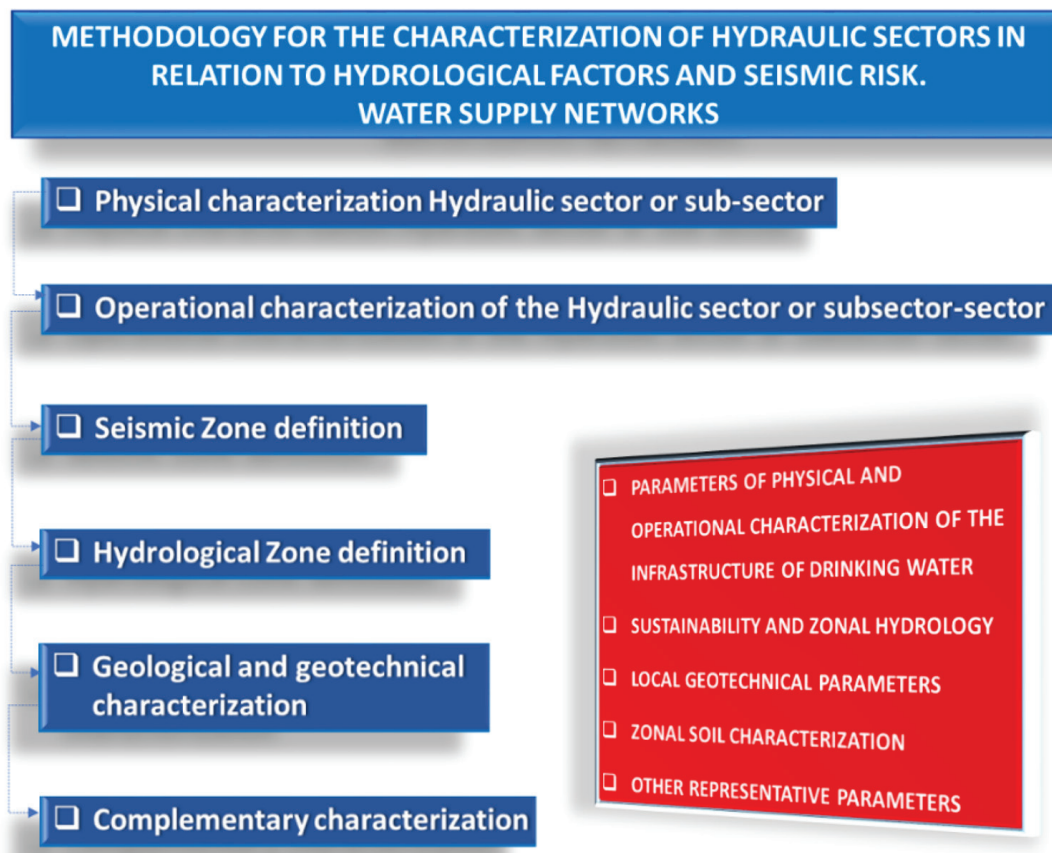

Figure 8: Methodology for the characterization of hydraulic sectors in relation to hydrogeological factors and seismic risk in water supply networks. (EMUASA). 


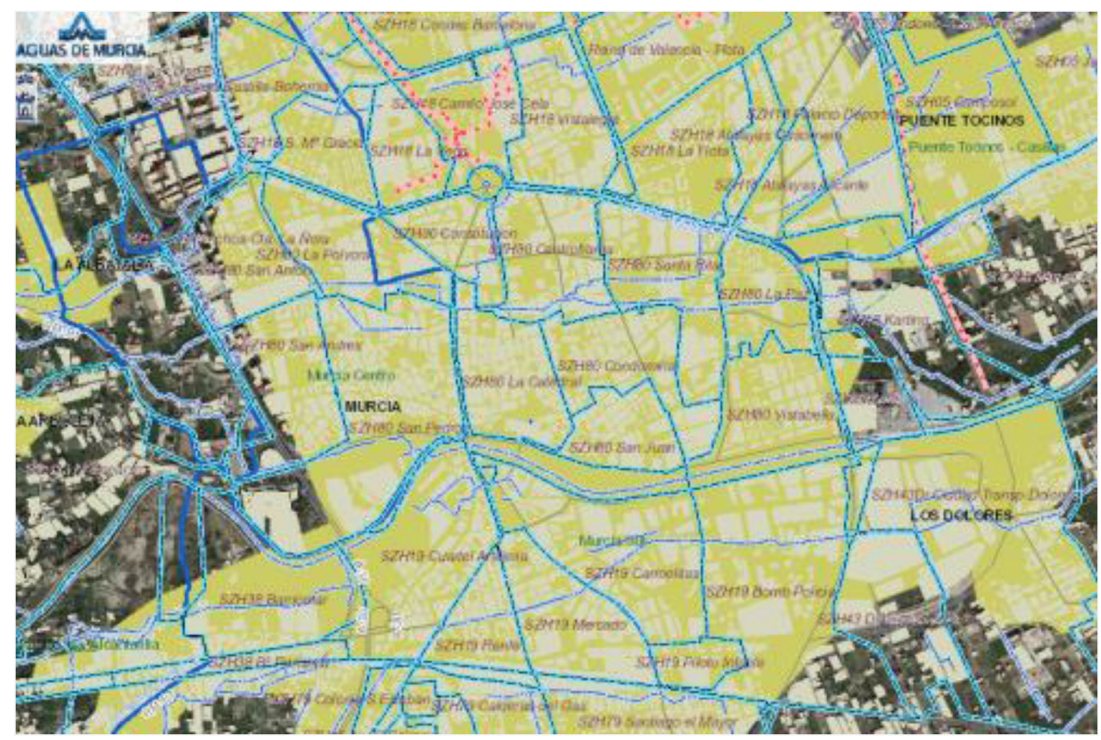

Figure 9: Hydraulic subzones in various neighborhoods of the City of Murcia. (EMUASA).

Likewise, it is a tool that allows structuring and channeling to the essential information necessary for real-time decision making. Next, we analyze various hydraulic sectors of the metropolitan area of the city of Murcia, where some main water supply pipelines are reflected, Fig. 10.

\section{Evolution of the age of pipelines in the network of Drinking water Murcia City}

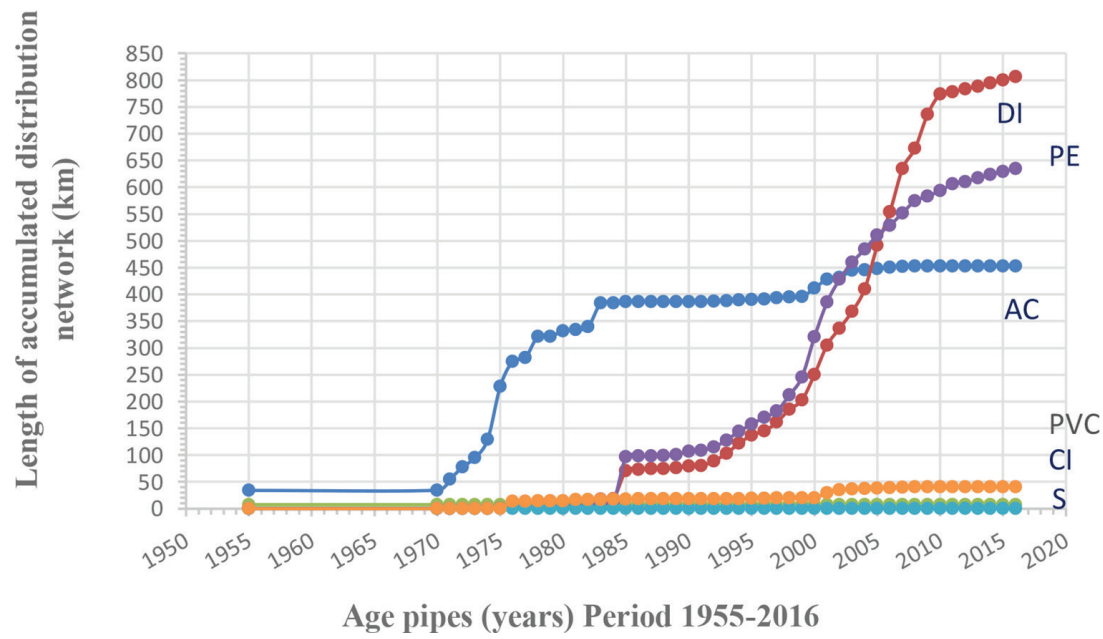

Figure 10: Temporal evolution and typology of material in the potable water distribution network of the City of Murcia (1955-2016) - DI (Ductile Cast Iron), PE (Polyethylene), AC (Asbeste cement), PVC (polyvinyl chloride), CI (Cast Iron), and S (Steel). EMUASA 
As already indicated, in non-cohesive plots located in strata higher than the water table or in the transition zone, differential settlements can be generated with displacement of the connections or even rupture of the pipe in extreme conditions, being the heterogeneity and the different stratification of the terrain, a susceptibility factor, which can influence the behavior of linear hydraulic infrastructure [7], especially during seismic and/or hydrologic events, increasing damages and disrupting the system's integral operation. Next, there are representations of thicknesses of fills, limes and clays of the metropolitan area of the City of Murcia ( $\mathrm{B}^{\circ}$ de San Miguel, Sta. Eulalia, San Pedro, Infante J. Manuel, Vistabella, and others), Figs 11 and 12.

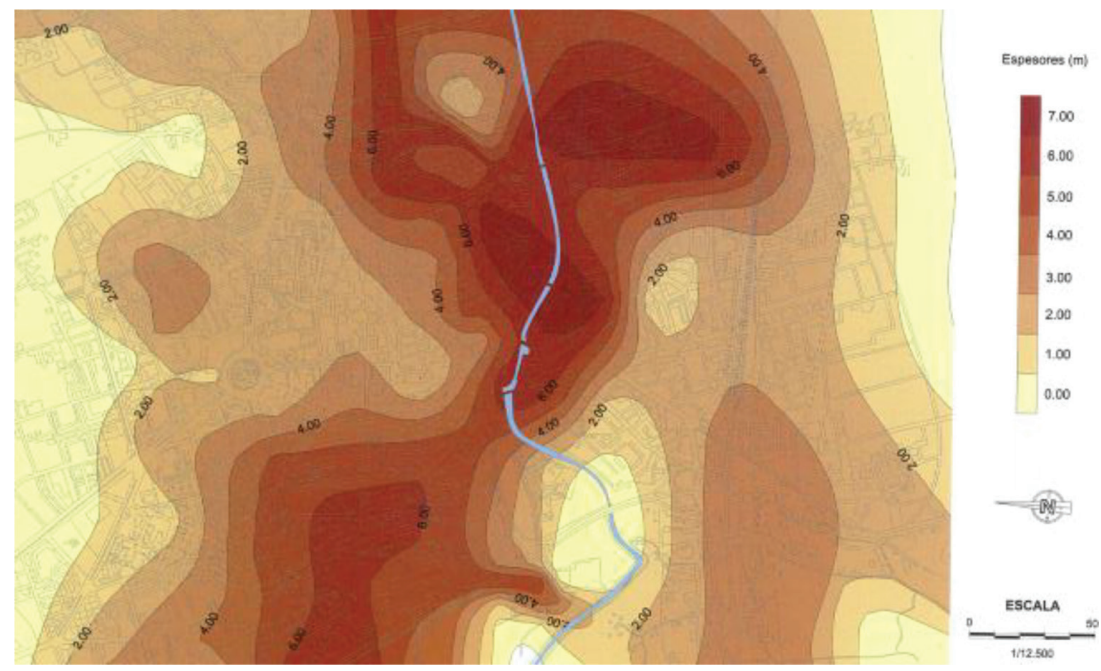

Figure 11: Thickness of fillings in the metropolitan area of Murcia. The Land Subsidence in the City and Metropolitan Area of Murcia IGME 2010.

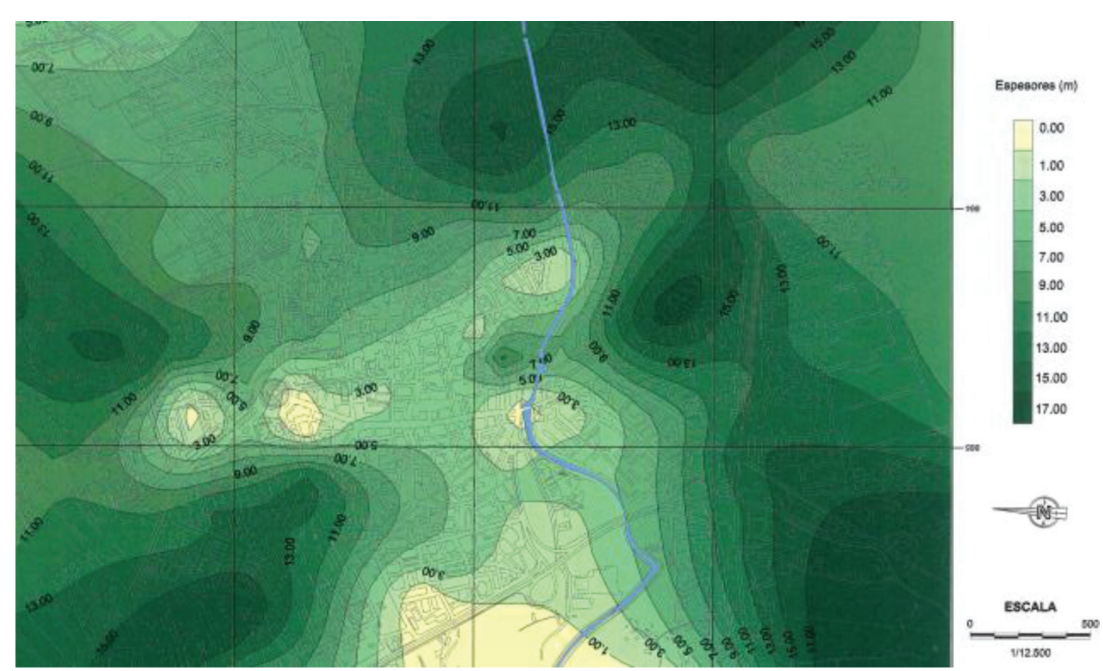

Figure 12: Thickness of clays and limes in the metropolitan area of Murcia. The land Subsidence in the City and Metropolitan Area of Murcia IGME 2010. 


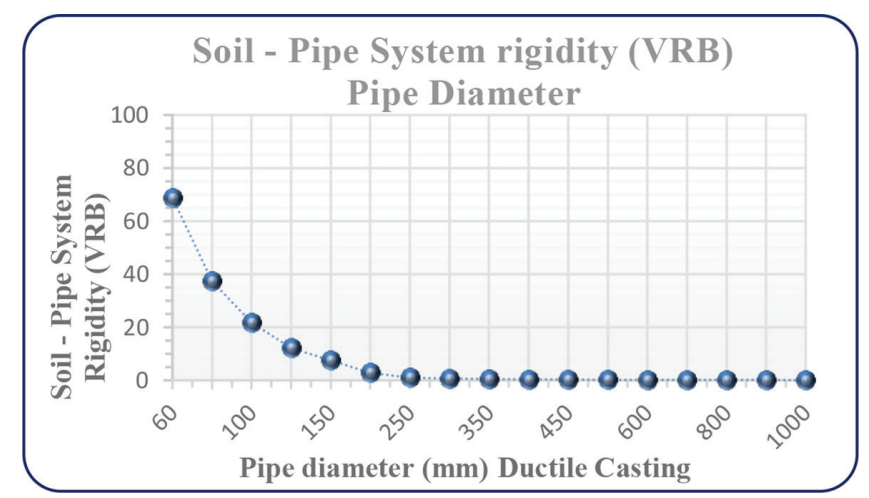

Figure 13: Representative graph of the Terrain structural system - Ductile cast iron pipe and pipe diameter (EMUASA).

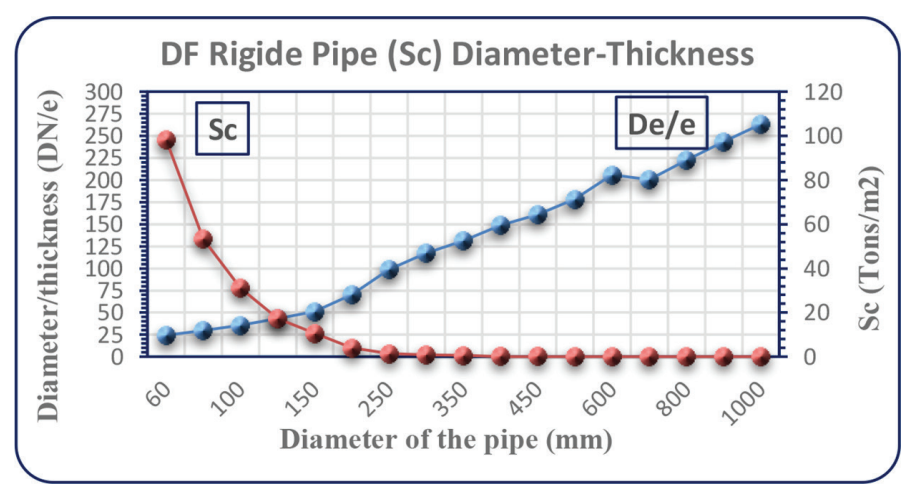

Figure 14: Representative graph of the evolution of the long-term circumferential stiffness, external diameter and installed DF pipe thickness (EMUASA).

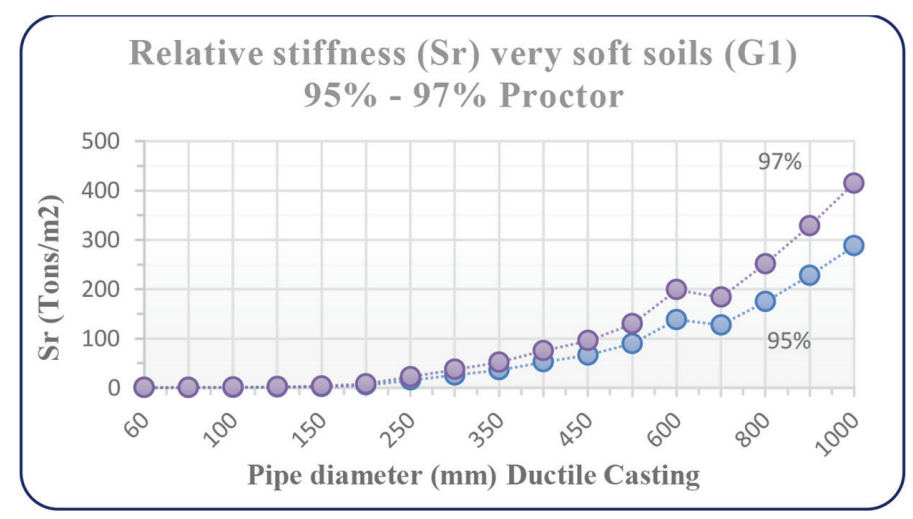

Figure 15: Relative stiffness (Sr) in very soft soils according to pipe diameter and degree of compaction of the filling. Ductile Casting (EMUASA). 
Table 3: Classification of drinking water pipes according to the level of service and the period of return of occurrence of an earthquake. (FEMA Seismic Guidelines for Water pipelines 2005).

\begin{tabular}{|c|c|c|c|c|}
\hline $\begin{array}{l}\text { Pipe function } \\
\text { class }\end{array}$ & Importance & Tipology & $\begin{array}{l}\text { Probability of } \\
\text { exceedance } 50 \text { years }\end{array}$ & $\begin{array}{l}\text { Return period } \\
\mathrm{T} \text { (years) }\end{array}$ \\
\hline I & Very low to None & - & $100 \%$ & Undefined \\
\hline II & Ordinary, normal & - & $10 \%$ & 475 \\
\hline III & Critical & - & $5 \%$ & 975 \\
\hline IV & Essential & & $2 \%$ & 2475 \\
\hline
\end{tabular}

Table 4: Calculated values of PGD, based on FEMA Seismic Guidelines for Water pipelines 2005 recommendations, according to failure movement and service level of the pipeline.

\begin{tabular}{lll}
\hline Pipe function & Design movement (PGD) & Peak ground displacement (PGD) $(\mathrm{m})$ \\
\hline I & - & - \\
II & $1 \mathrm{AD}$ & 0.631 \\
III & $1.5 \mathrm{AD}$ & 0.946 \\
IV & $2.3 \mathrm{AD}$ & 1.451 \\
\hline
\end{tabular}

Following are some graphic representations showing the behavior of drinking water pipes according to their physical characteristics (material nature, diameter, ..), and circumferential stiffness, as well as the nature and degree of soil compaction (Figs. 13, 14 and 15).

According to studies included in the FEMA Seismic Guidelines for Water pipelines 2005 [8], in relation to drinking water pipes, pipes are classified into 4 classes according to the degree of importance and the period of return $\mathrm{T}$ of occurrence of an earthquake, as indicated in the Table 3.

By means of these recommendations, the parameter PGD (Peak Ground Displacement) was obtained, as well as the maximum slip (AM) generated for an earthquake of magnitude 6.8 (maximum probable), according to the characteristics of the Carrascoy Fault located at $6 \mathrm{Km}$ of the metropolitan area of Murcia, as indicated in the Table 4 [9].

The value of these parameters has been calculated based on the equations proposed by (Wells \& Coppersmith, 1994) [10].

\section{CONCLUSIONS}

The analysis of the geological and geotechnical parameters of the area of implementation of the exposed methodology is essential for the development of a comprehensive, preventive and resilient planning for the Sustainability of the linear infrastructure of urban supply.

This research proposes the structured planning of the different phases that define the integration of the characterization of the potable water supply system and its interaction with the hydrogeological zonal risks.

The different milestones that define the methodology that is proposed are characterized by hydraulic sectors or subsectors and are described below: 
- Characterization of hydraulic sectors and subsectors.

- Identification of pressure zones.

- Physical characterization of the Linear Infrastructure according to the main components listed.

- Operational characterization of the Hydraulic Sector or Subsector according to the described parameters.

- Incorporation of parameters that characterize water quality.

- Location of 'sensitive' subscribers, and/or strategic.

- Definition of seismic parameters representative of the area.

- Definition of hydrological and hydrogeological parameters representative of the area.

- Characterization of the most representative parameters that define the geology and geotechnics of the area.

- Additional information, relevant to characterize the hydraulic sector.

Through the characterization of the linear Infrastructure of drinking water supply linked to the geological and geotechnical definition of the particularized area of analysis, it allows its correlation with the probable degree of affectation of the same, in the case of a seismic event, as well as the risks associated with it.

\section{ACKNOWLEDGEMENTS}

The authors wish to thank EMUASA their cooperation in conducting this study, without which this study would not have been possible.

$P G A=$ Peak ground acceleration $\left(\mathrm{g}\right.$ o $\left.\mathrm{m} / \mathrm{s}^{2}\right)$

NOTATIONS

$P G V=$ Peak ground velocity $(\mathrm{cm} / \mathrm{s} \mathrm{o} \mathrm{m} / \mathrm{s})$

$P G D=$ Peak ground displacement $(\mathrm{cm} \mathrm{o} \mathrm{m})$

\section{REFERENCES}

[1] Tsige, M. \& García Flórez, I., Proposed geotechnical-amplification classification of geological materials in Murcia. Geogaceta, 40, pp. 39-42, 2006.

[2] Akkar, S. \& Bommer, J.J., Empirical equations for the prediction of PGA, PGV and spectral accelerations in Europe, the Mediterranean Region and the Middle East. Seismological Research Letters, 81(2), pp. 195-206, 2010. https://doi.org/10.1785/gssrl.81.2.195

[3] Manual para Enfrentar Inundaciones Ocasionadas por Rotura de Matrices de Agua Potable o Colectores de Aguas Servidas. Access, 15 Junio 2016, available at: http:// www.siss.gob.cl/577/w3-printer-8208.html.

[4] Borcherdt, R.D., Estimates of site-dependent response spectra for design (Methodology and Justification). Earthquake Spectra, 10, pp. 617-653, 1994. https://doi.org/10.1193/1.1585791

[5] SRMLIFE. Development of a global methodology for the vulnerability assessment and risk management of lifelines, infrastructures and critical facilities. Application to the metropolitan area of Thessaloniki. Research Project, General Secretariat for Research and Technology, Greece, 2003-2007.

[6] ALA. Development of guidelines to define natural hazards performance objectives for water systems, Volume I, prepared by ASCE, FEMA and NIBS, 2002. 
[7] ALA Wastewater system performance assessment guideline, Part I and II. FEMA and NIBS, 2004.

[8] ALA. Seismic guidelines for water pipelines, prepared by ASCE, FEMA and NIBS, 2005.

[9] Alexys Herleym Rodriguez Avellaneda, Ingeniero Civil, especialista en Telecomunicaciones. Tesis "Análisis y evaluación de riesgo sísmico en líneas vitales. Caso de estudio Bogotá D.C.”. Universidad Nacional de Colombia, 2011.

[10] Wells, D.L. \& Coppersmith K.J., New empirical relationships among magnitude, rupture length, rupture width, rupture area and surface displacement. Bulletin of the Seismological Society of America, 84, pp. 974-1002, 1994.

[11] RISMUR II Seismic Risk Plan of Murcia, 2015. 